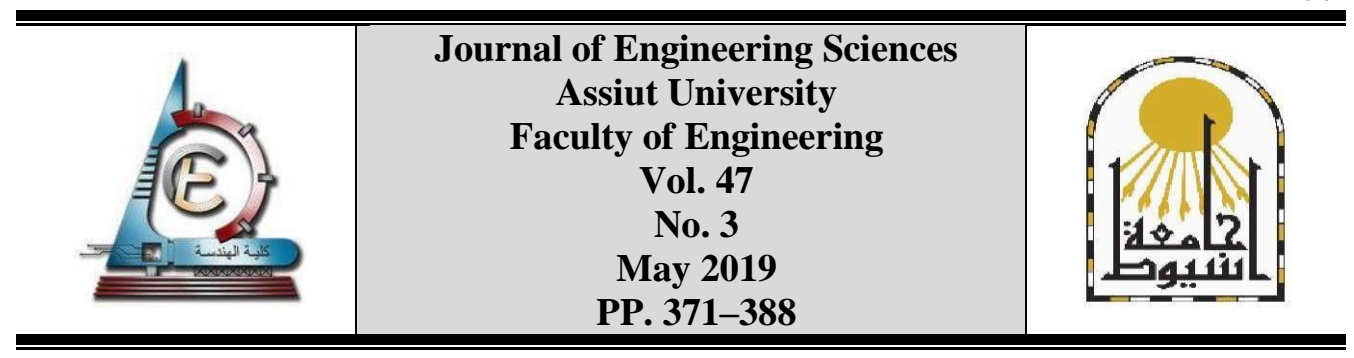

\title{
TOWARDS ENVIRONMENTALLY RESPONSIVE ARCHITECTURE: A FRAMEWORK FOR BIOMIMIC DESIGN OF BUILDING'S SKIN
}

\author{
Marwa N. Charkas \\ Faculty of Engineering, Pharos University, Alexandria, Egypt \\ marwa.charkas@pua.edu.eg
}

Received 3 February 2019; Accepted 8 February 2019

\begin{abstract}
As it has always been, nature is the main source of inspiration. Its ability to sustain the coexistence of an endless number of organisms in perfect dynamic balance makes its behavioral patterns as a model to be followed. The key principle of these patterns is adaptation. Understanding its related concepts helped to interpret the continuous organisms' change to achieve the equilibrium that is responsible for sustainability. However, this pattern is widely inspiring researchers to find solutions to a more and more sophisticated complexes beyond the limits of their scopes. One of these current emergent problems is energy conservation in general and at architectural domain in particular.

This paper investigates the potentials of 'Biomimicry' - defined as an innovation inspired by nature- to come with original visions to building's skin as a mediator surface between internal and external environmental conditions. It addresses a number of environmental concerns; energy balance, humidity, temperature, visual perception, noise, carbon dioxide concentration, and light intensity that the building's envelop has to reconfigure their performance moving from the outer environment to the inner one. It presents a framework for biomimic design of building's skin based on detailed studies for number of biomimic design processes, adaptation techniques and strategies for skin configurations. It also makes an in-depth analysis to a number of related examples to show the updated trends in adaptation related techniques. Finally, it comes up with recommendations concerning the most appropriate techniques that could be utilized to come with innovative solutions inspired by the native Egyptian biological conditions.
\end{abstract}

Keywords: Biomimicry, Energy Conservation, Building Skin, Adaptation, Biomimic Design process

\section{Introduction}

The increasing global concerns about energy related issues have profoundly affected the architectural domain [1]. Nowadays, a fourth pillar has been added to the classical Vitruvius triangle model for architecture that is 'Energy'. Statistically, large portion of energy used in buildings is directed towards creating controlled comfortable interior conditions regardless the external conditions. This adds another role to the external building skin as to manage the relationship between internal and external domains. While the internal comfort conditions are almost fixed according to the well-established standards, the external conditions widely vary. The unremitting change in external climatic 
conditions dictates a dynamic responsive typology of external building skin to make the best use of surrounding environmental conditions at immediate time.

Regarding the excessive role that building skin plays in mediating the external environmental conditions, a major part of design problem is shifted to focus on building skin configurations. The focus of many designs now is to design a building skin that behaves as a dynamic responsive system. However, this matter has brought biological domain to the heart of architecture concerns. The remarkable adaptability of natural organisms to extreme environmental conditions has become a main source for architects' inspiration [2]. Actually, biology related concepts (biomimic, biomorphic, biophilic, ......etc.) has been experienced in architecture since the early civilizations. But, the new technologies, developed rational methodologies, and cumulative experiences in this domain have brought new and innovative solutions to the long experienced problems.

In VDI-Guideline 6220 (2011) [3], a group of experts presented a definition to Biomimetics that gives an insights to the differences between biomimetics and conventional methods/products [4]: 'Biomimetics combines the disciplines of biology and technology with the goal of solving technical problems through the abstraction, transfer, and application of knowledge gained from biological models. Biological models in the sense of this definition are biological processes, materials, structures, functions, organisms, and principles of success as well as the process of evolution itself' [3]. However, this definition draws a roadmap for different approaches that biological based inspiration to architectural domain could be tackled through. Three main directions could be distinguished in this regard: biological models' based adaptation behaviors, studies of technological advancements, and the linkage between these two domains. These overlapped and interconnected domains are double-edged sword, on one hand, they increase the complexity of architectural problem statement, and on the other hand they had opened a new venue for innovation and creativity.

This paper develops a methodological approach to building's envelop design based on biomimic understandings. It correlates different / related areas of investigation in a comprehensive framework. Three main areas are highlighted in this framework: the challenges that face building skin as a mediation between outside environmental factors and inside user comfort requirements, the correlation between these challenges, and biological based adaptation behavior whether it is based on dynamic mechanisms or static strategies, and finally is the cyclic typology of the biomimicry design process. The time is also addressed as the rhythm of all of these processes. The paper presents two examples to show the applicability of the developed framework in analyzing the correlation between design challenges and adaptation techniques. In addition, a batch of examples is driven to validate the claim about important synchronized relationship between architecture futuristic visions, and advancement potentials offered by technologies as the guarantee to come with evolutionary endless releases of featured architecture derived from the same bio-inspiring features based on informative feedback process. Finally, the paper discusses the potentials of introducing the biomimicry design based architecture in Egyptian context based on 'the Gate' a new urban development project located in Heliopolis, Cairo.

\section{Biomimicry design process}

In biomimicry approach to building design, the building skin is seen as an adaptation media to mediate the external environmental conditions. This environmental adaptation 
Marwa N. Charkas, Towards environmentally responsive architecture: A framework for ..........

design process is a focus of number of studies. According to López, et al. [5], this process could be addressed in four steps; defining climate data and user demands, determining environmental issues, pointing out challenges and functions, and the last step is to define adaptive behaviors. Each of the aforementioned steps contains a number of investigations and analytical studies to come with the more appropriate adaptive behaviors among the wide pallet of these patterns.

- The first step: The climatic data should be identified according to the Worldwide Bioclimatic Classification System as the outer environmental conditions. Detailed aspects are accordingly identified based on the identified season and the period whether daytime or night-time. In addition, the user comfort levels has to be defined according to the level and type of activity using the national and international standard regulations for buildings such as ASHRAE (American Society of Heating, Refrigerating, and AirConditioning Engineers), and BECP Building Energy Codes Program.

- The second step: defines four environmental concerns that the facade has to reconfigure their performance moving for the outer environment to the inner one. These aspects are; humidity or water availability, temperature, atmospheric carbon dioxide concentration, and light intensity.

- The third step: defines a number of challenges/functions as related to the specific climate data and user requirements. These functions are as follows; exchange, gain, retain, dissipate, prevent, conserve, transport, lose, and regulate. Actually, each of the aforementioned environmental issues is linked to a number of these functions.

- The fourth step: is developing the appropriate adaptation behavior. According to López, et al. [6], it is divided into a dynamic mechanism and static strategy. The former, is showing a certain kind of observable motion resulting in changes in the envelope configuration through moving parts. These types of moving mechanisms include: folding, sliding, expanding, creasing, hinging, rolling, inflating, fanning, rotating or curling. The latter -static strategies- the adaptability is realized through morphological features, such as density, patterning or geometrical strategies, also changes in specific properties of materials. It depends on reflection, absorption or exchange of energy from one form to another.

Badarnah, [7] highlights the interdisciplinary nature of biomimetic design process. She points out three different domains as to be engaged to generate a design concept; problem, nature, and solution as shown in figure (1). She comes up with a design process that overlaps with López, et al. one in its four steps. The developed process moves from abstract strategies to evaluation and validation step to solve the identified problem. She anticipates for optimizing the used strategies extracted from different systems to achieve design solutions as a consequence of the very complicated multidisciplinary process as to transform strategies from nature into technical solutions.

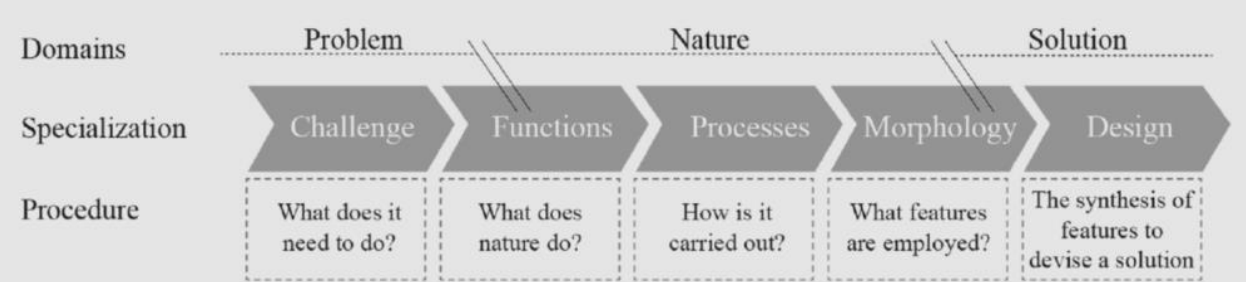

Fig. 1. The biomimicry linear design process. Source [8] 
Adding another dimension, the Challenge to Biology Design Spiral developed by Carl Hastrich, presents an approach consists of five steps to guide designers while going through a biomimetic design process [9]. As shown in figure (2), the design stages are arranged around "outward spiral", and each of them is wide-ranging, "non-product specific" [10]. While moving around the spiral in a clockwise direction it solves some aspect of the problem. Each complete revolution refines the achieved results and resolve deeper aspects of the challenge [9]. Comparing to the linear design processes, this design spiral with its small feedback cyclic alterations based on applying natural adaptation principals, is considered as a more appropriate tool to help designers come with new developed designs. According to the Biomimicry Institute, it's endless processes that resample the natural concepts, "after it resolves one challenge and evaluates how it compares to Life's Principles, most likely another problem appears, and the process begins again" [11].

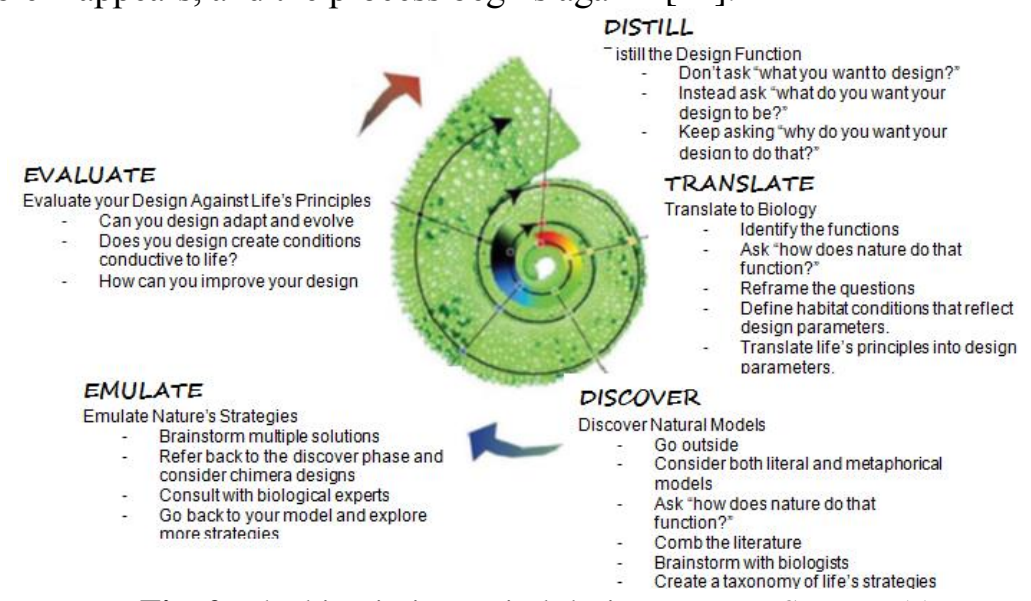

Fig. 2. The biomimicry spiral design process. Source [11].

\section{The biomimic adaptation behavior}

According to Ferguson et al. [12] adaptability is defined as "the ability of a system to deliver intended functionality considering multiple criteria under variable conditions through the design variables changing their physical values over time". Regarding climate adaptive building shells (CABS) Loonen et al. [13] highlights three important behavior platforms, adaptability, multi-ability, and evolve-ability. Adaptability is the building shell attributes that dynamically response and interacts with the surrounding conditions. This concept is utilized to respect the individual user compared to other approaches that aims at achieving the best average for all users according to the well established standards.

Multi-ability is another concept presented by Hofman and Dujardin, [14]. It is based on the potentials that the design affords to meet the changing needs over time. They use an example of 'balcony that can be folded' as a metaphor for meeting the continuous external conditions and users' preferences. Compared to adaptability, multi-ability is more efficient in resources' consumption as multiple objectives could be achieved consecutively, rather than concurrently [12]. It permits for different changes through a set of optimized states. That's way it is more efficient in resources' consumption. Another characteristic of multiability is the potential for variety of spatial expression. Each part of the building envelope can take different articulation properties based on its position of the overall building shell. Accordingly, any part of the building shell could behave independently as a reaction to the 
Marwa N. Charkas, Towards environmentally responsive architecture: A framework for ..........

surrounding detailed conditions or according to the specific comfort requirements determined by the individual user in different zones of the building [13].

Unlike adaptability, and multi-ability that deal with short-span variations, Evolvability concept focuses on a long-term flexibility in dealing with the unexpected surrounding conditions [15]. The need for this concept is growing dramatically as the unprecedented changes in building requirements and surrounding conditions over time. Evolving is seen as a positive side effect' rather that an aim of the design itself. It works as an add value to the design product 'Building' as it keeps an open end to its shell's configuration that give it the chance to react responsively to changes in future. However, changes could be external or/and internal. they for example include; climate change, changing urban environment, wearing of the façade, ... etc. as external changes and organizational function changes of the building, new space layout as internal ones. For all of this wide spectrum of changes, the evolving responsive building shell is the guarantee for keeping the performance of the building envelop in a satisfactory level regardless the unforeseen future conditions [13][16].

\section{Evolution biomimicry design process}

The long experiencing practices of biomimic design for building's skin has proved its operative cyclic typology. Figure 7 shows a series of biomimic based building skin designs :( Institute du monde Arab in Paris, US Pavilion 67, The Al Bahar Towers in Abu Dhabi, and Doha Tower in Doha). They are linked chronologically to show the importance of feedback stage in the evolutionary biomimic design process. However, the new updates based on advancements in technology and computer based applications plays a supportive role to this evolutionary process. One of the leading examples is Institute du monde Arab in Paris designed by Jean Nouvel and Architecture studio (completed 1989). Its adaptive building skin technique is inspired by the human eye pupil responsive adaptation to light [17] (figure 4). Its opening diameter is inversely proportional to the amount of day lighting. However, the designer re-experienced the 'Mashrabiya' -a traditional feature of Islamic architecture used as windows' cover to filter the mass solar radiation in hot arid zones- based on this biomimicry interpretation to introduce his very inspiring building skin. The southern façade is made out of (240) 24 x 10 grid of square units consists of a central circular photosensitive shutters working as a Mashrabiya that controls the penetration of solar radiation. The façade works as an interactive closed loop system. Sensors along the façade are spread to collect data about radiation level [18]. Based on data analysis, small motors operate to control the level of shutters openness and accordingly the permitted light to enter the space. However, at the operation level, this developed façade system proved to be inefficient due to mechanical problems [19]. Many parts of the mechanical system were broken and their maintenance and replacements is not easy. As a result, this delicate inspiring system is no longer working [20].

Actually, this Nouvel's stimulating building is not the first to rely on the biomimicry of eye pupil as source of inspiration. Buckminster Fuller design for US Pavilion 67 is an early example for using building skin kinetically to control the inlet of external environmental onditions based on eye pupil mimicry (figure 3). The iconic design is shaped as a geodesic dome structure covered with hexagon panels. They are made of plastic and photochromatic glass covered with a tinted plastic film to permits the surface to breathe [21]. In addition, the original design by Fuller links the shading devices to a central computer control that resets the orientation of these devices every two hours to track the direction of sun motion. In fact, this ambitious design was not entirely executed due to technical 
problems at its time [18]. Nowadays, this kinetic responsive -originally proposedbiomimic design could be realized due to the current technologies. However, this shows that synchronization between design ambition, and available technology limitations has to be realized as a guarantee to a successful biomimic design.

Based on similar mimicry inspiration and more advanced technology, two office buildings in Abou Dhabi were constructed and occupied in 2012. The Al Bahar Towers owned by the Abu Dhabi Investment Council and designed by AEDAS- represent a contemporary version of the dynamic responsiveness to surrounding environmental conditions relying on an eye pupil and Mashrabiya inspiration [17]. The building façades are covered with more than 1000 dynamic translucent umbrella-like hexagonal pattern made of stretched PTFE (polytetrafluoroethylene) [22] (figure 5).

They are controlled by a centralized building management system (BMS) and operate in response to sun movement. However, the role played by this developed biomimic system is comprehensive. The AEDAS shows that "it reduced glare, improved daylight penetration, less reliance on artificial lighting, and over 50\% reduction in solar gain, which results in a reduction of $\mathrm{CO} 2$ emissions by 1,750 tones per year" [30].

Another modern example based on the same biomimicry inspiration source is Doha Tower designed by Jean Nouvel and completed in 2012. The building façade is a composite layered one. One of these layers is a "modernized mashrabiyya". It is composed of a multi layered geometric motif (four layers) superimposed in different densities and scales to affect dramatically the interior penetrated light. The densities of these layered differs according to façade's orientation. Its opacity is $25 \%$ at the north one, $40 \%$ at the southern one, and 60\% at both west and east façades [22] (figure 6). However, the façade system in this case depends on an integrated comprehensive approach. Both of kinetic screen and the curtain wall, made out of reflective glass, and built with roller blinds are working together to perform a comprehensive solar protection system [24]. Using this developed scheme is proposed to reduce cooling load by about $20 \%$.

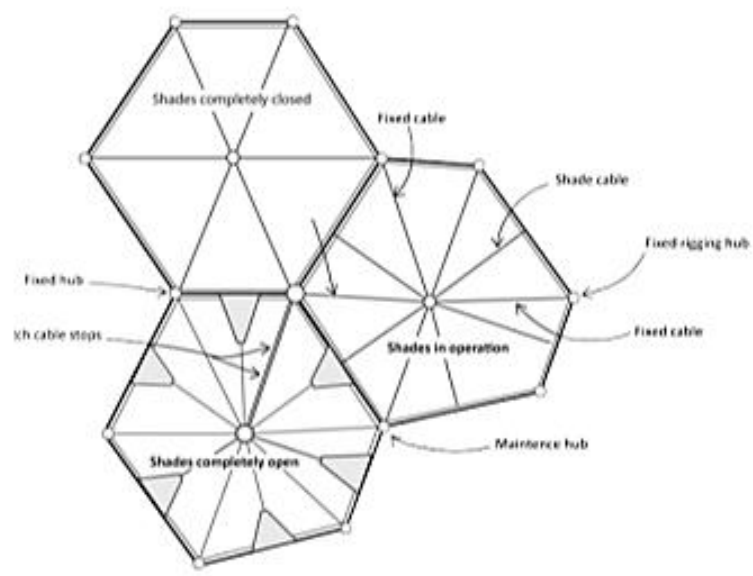

Fig. 3. Hexagonal shutter of American Pavilion 1967 Designed by: Buckminster Fuller. Source: [18].

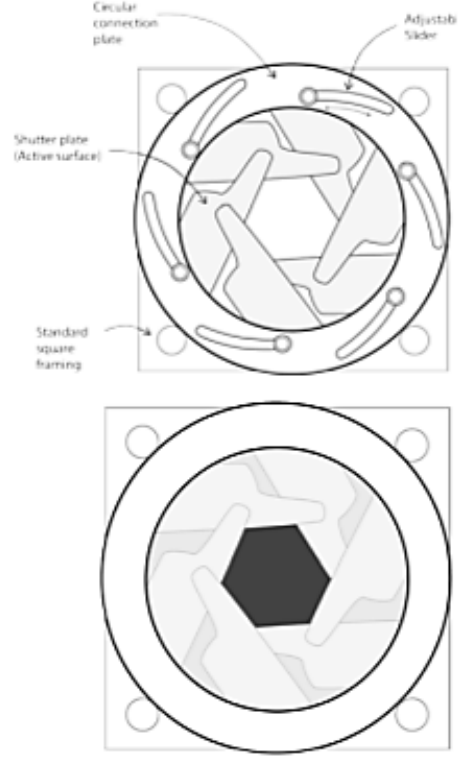

Fig. 4. Kinetic shutter panel of Institute Monde Arabe,

Designed by Jean Nouvel. Source: [18]. 


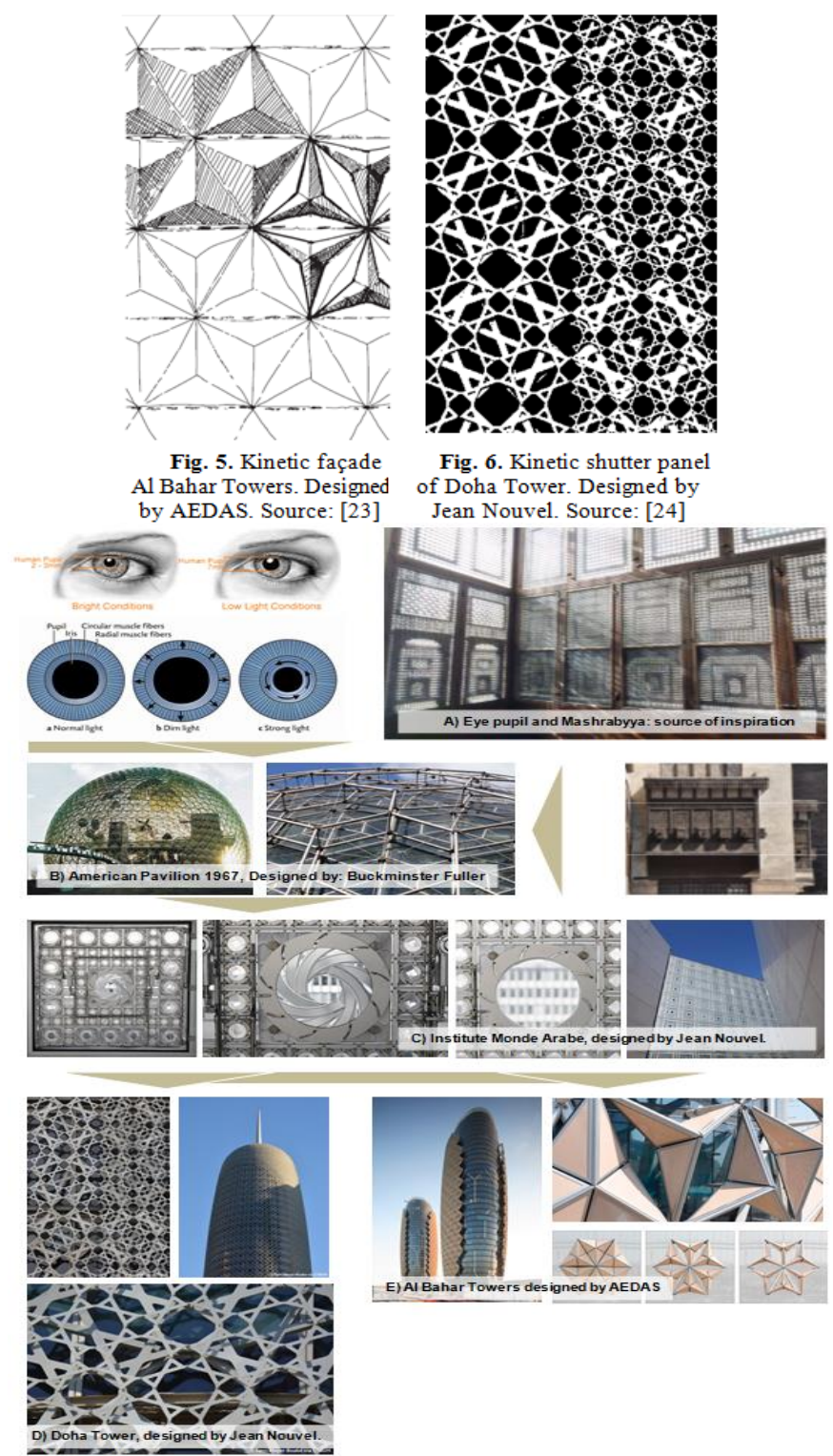

Fig. 7. Examples of evolution biomimicry design process. Sources are as follows:
A) [25],
B) [26], C)
C) [27], D) [28],
E) [29]

\section{Biomimic design framework}

The design framework proposed in this paper, correlates all of the biomimicry design aspects within the comprehensive understanding of the biomimicry spiral design process. It consists of three main parts as follows:

- The first is challenges that face building skin in mediating the external conditions. The external building envelop as interference surface behaves according to many physical interactions. They are blocking, filtering, converting, collecting, storing for example and they are usually used as mix and match strategies [13]. Many references had add to this list [7] [8], [31], [4], [2] as shown in the framework. In addition many studies have determined environmental domains to investigate the 
fields of these physical interconnected performances. López, et al. [5], determines four domains (humidity or water availability, temperature, atmospheric carbon dioxide concentration, and light intensity). Another list is proposed by Loonen, et al., [13] (thermal, optical, air-flow, and electrical). The overlapping areas of these four concerns resulted in fifteen different possible combinations to show the related physical interactions of 'climate adaptive building shell' concept as shown in figure (8). The framework addresses number of these domains.

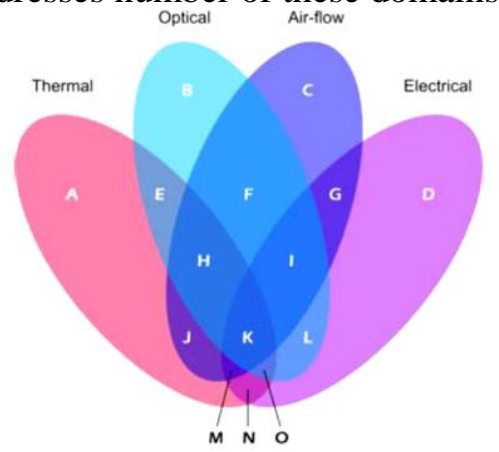

Fig. 8. Physical related interactions of biomimicry adaptive building shell. Source: [13]

- The second is the correlation between these challenges, and biological based adaptation behavior. Actually many studies has addressed these adaptation patterns in depth according to many classifications. The framework (figure 9) follows classification developed by López, et al. [6] as it presents an analogy between a building and a plant regarding their mutual characteristics concerning limited moving possibility. The framework classifies adaptation behavior as either dynamic mechanisms (kinetic architecture) or static strategies (concerning morphological features, or material properties).

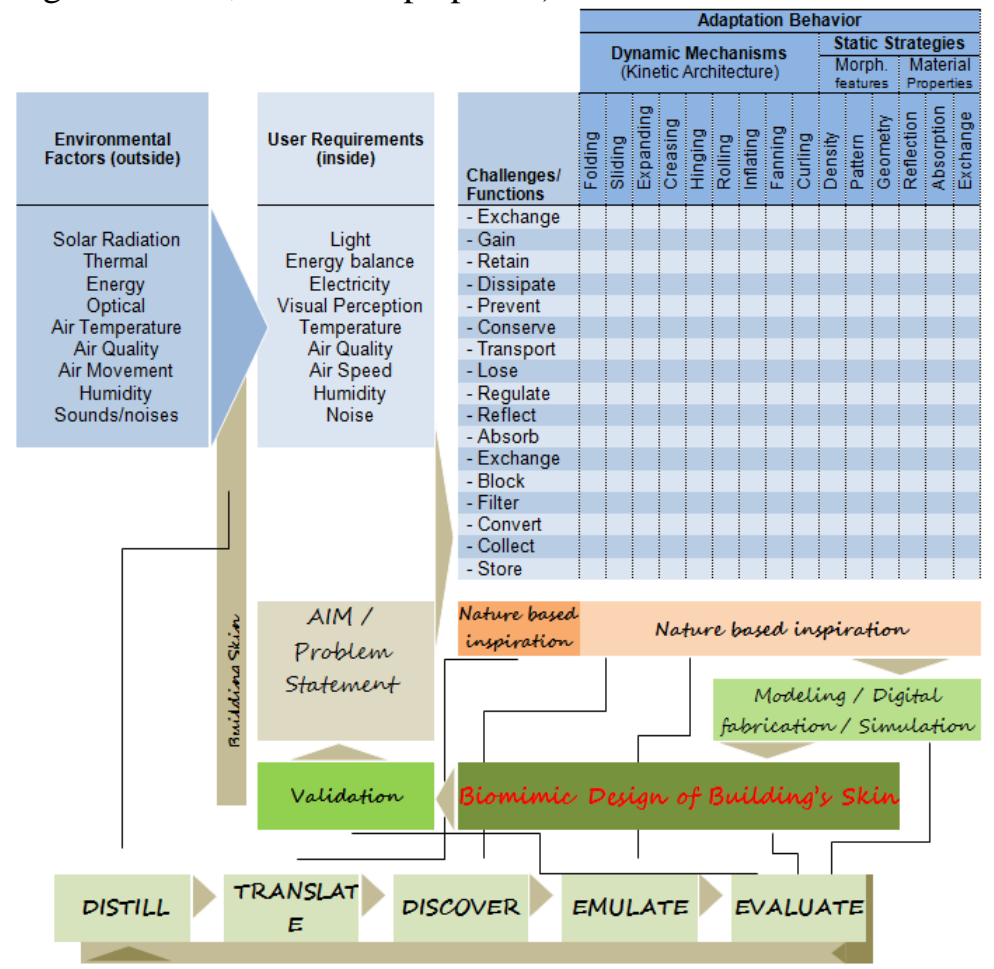

Fig. 9. Developed framework for Biomimic Design of Building's Skin. Source (Author) 
Marwa N. Charkas, Towards environmentally responsive architecture: A framework for ..........

- The third is the cyclic typology of the biomimicry design process within an understanding of different temporal rhythms. Actually, the interactive typology that shapes the relationship between building skin and surrounding environment highlights the temporal aspect as a key issue. Cyclic pattern of effective time widely differs. It ranges from the order of sub-seconds to impacts that is expands along the building lifetime. According to Loonen, et al., [13], the time scale in case of climate adaptive building shell consists of: seconds, minutes, hours, diurnal, and seasons.

- Seconds represent the random natural short time fluctuations. Movement in wind pressure based skin system based on the variation in wind speed and direction is a good example. Sensors that detect user's proximity and direct building skin configuration in immediate way are another example.

- Minutes are the characteristic time span that realizes cloud cover and daylight availability. In practice, this time scale is responsible for the most of concepts developed to mediate external conditions especially availability of solar radiation. Accordingly, most of strategies developed to optimize daylight performance and solar shading for controlling energy gain/loss and visual comfort, are controlling the building's skin degree of transparency in a time scale of minutes.

- Hours controls a wider range of changes. Among these are tracking the path of the angular movement of the sun, the internal and external change of temperature, and finally the adaptations of building skin to the temperature exciter [32].

- Diurnal is concerned on one side with the fixed micro environmental cycles, and on the other side with the pattern of building's occupancy. This fixed 24 hour pattern is clearly observed in surrounding conditions like ambient air temperature and availability of solar radiation [13]. However, this pattern is utilized in many applications regarding the climate adaptive building shell such as the adaptable thermal storage in solar barrel wall, and the nocturnal release of thermal energy via roof ponds with movable insulation [33].

- Seasons offer a wide range of variety for surrounding environmental conditions. Adapting to the cyclic varieties characterizing different seasons is responsible for most of the featured applications of the climate adaptive building skin especially in medium and high latitudes [13].

Buildings adapted to these consistent cyclic rhythms proved radical performance benefits. The bidirectional thermal diodes presented by Pan and Jeng, [34] are a good example for seasonal adaptable building skin. The developed wall responses to temperature differences between internal and external surrounding environment and the thermal load of the location. This is based on its ability to either boost or quell heat transfer across its boundary.

\section{Analytical examples}

To investigate the applicability of the developed framework, the paper presents an analytical study to the correlation between design challenges and adaptation techniques in two examples. The first is The Minister of Municipal Affairs \& Agriculture (MMAA) in Qatar and the second is ThyssenKrupp Quarter Essen Q1 building in Essen, Germany. They are selected as they are showing different strategies to deal with contrast external environmental conditions. 


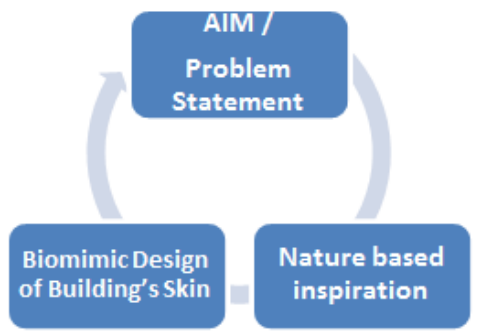

Fig. 10. A brief Biomimic Design process of Building's Skin followed while analyzing examples. Source (Author)

Each of the two selected examples is analyzed within the outlines of the proposed frame work and following the shown design process. It firstly discusses the design problem that shapes the external environmental challenges for 'Building Skin'. Then it shows the 'Biomimic Design of Building's Skin' developed according to "Nature-based inspiration". And finally it illustrates the Adaptation Behavior used in design intervention.

\subsection{Example I. The Minister Of Municipal Affairs \& Agriculture (Mmaa) In Qatar}

Designed By: Bangkok-based Aesthetics Architects

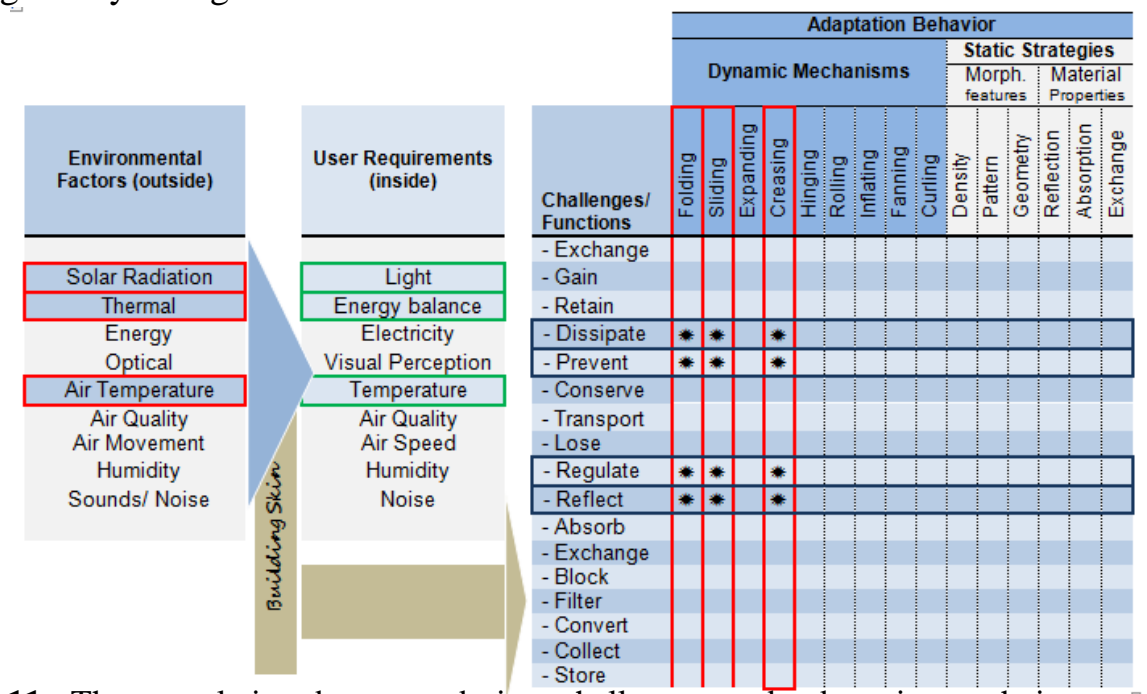

Fig. 11. The correlation between design challenges and adaptation techniques applied to the Minister of Municipal Affairs \& Agriculture (MMAA) in Qatar. Source (Author)

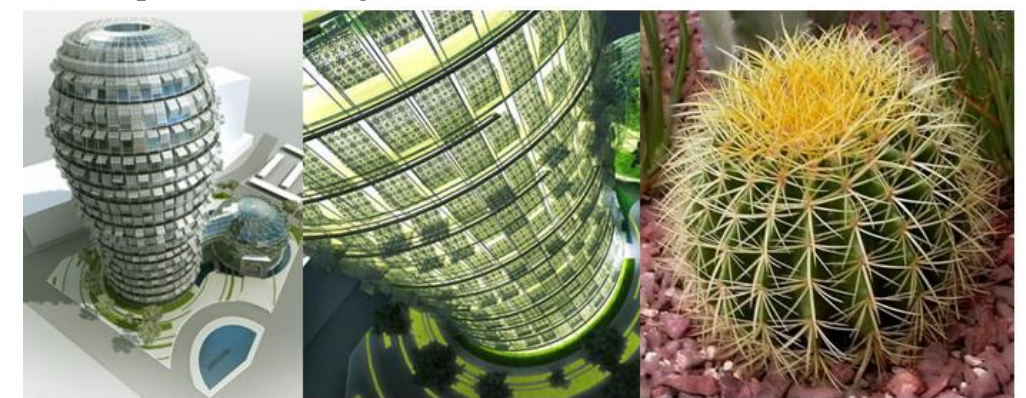

Fig. 12. Biomimicry design based cactus inspiration for the Minister of Municipal Affairs \& Agriculture (MMAA) in Qatar. Source [35] 
Marwa N. Charkas, Towards environmentally responsive architecture: A framework for ..........

The External Environment (Environmental Factors): This office building is located in hot dry climate. Its location scarcely receives rainfall during winter months. It amounts not more than $100 \mathrm{~mm} / \mathrm{y}$. The harsh external conditions include very high solar radiation, thermal mass, and air temperature. In summer, the average temperature scores around $42 / 43^{\circ} \mathrm{C}$. It sometimes scores $45 / 47^{\circ} \mathrm{C}$ when the wind from the inland desert prevails.

- Challenges for 'Building Skin' Mediating the harsh surrounding environmental conditions to keep an acceptable level of user comfort requirements inside the building is the main challenge that faces the building's skin. Its function is to disperse, prevent, regulate, reflect and filter the excessive amount of solar radiation, thermal load, and very high wind temperature [36] (figure 101).

- Nature-based inspiration the design of the building's skin and its botanical dome annex is inspired by the way that a cactus survives in desert harsh hot and dry conditions (figure 12). The designer takes inspiration from the way a cactus retain water while performing transpiration. In addition, the shading role that the spines covering the cactus play in protecting the plant from the intense solar radiation is another inspiring feature in this project [37].

- Adaptation Behavior The design develops a smart shading system based on resembling the role of cactus spines. According to the external solar radiation intensity, these shading devices are automatically folding, sliding, or creasing to mediate these external conditions transferred to the internal space (figures $11 \& 12$ ). This developed biomimicry building skin allows lowering the mechanical cooling systems needed for the building to operate in a proper way.

\subsection{Example II. ThyssenKrupp Quarter Essen Q1 building in Essen, Germany.}

Designed By: JSWD Architekten + Chaix \& Morel et Associés

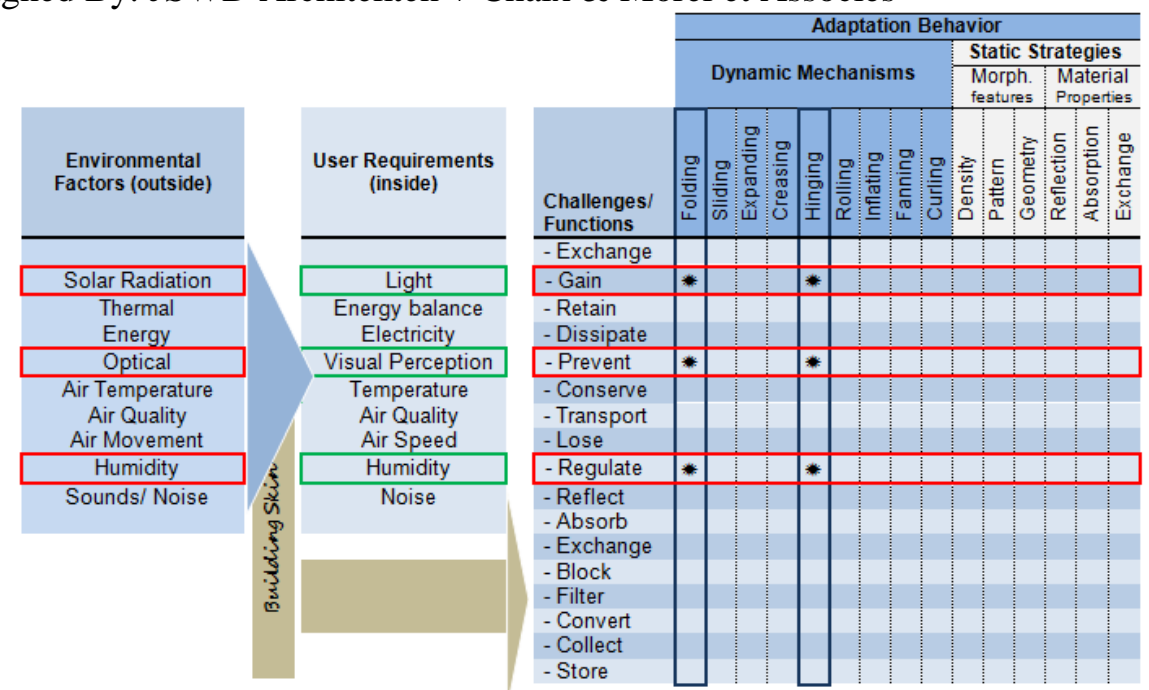

Fig. 13. The correlation between design challenges and adaptation techniques applied to ThyssenKrupp Quarter Essen Q1 building in Essen, Germany. Source (Author)

- The External Environment (Environmental Factors) ThyssenKrupp Quarter is located in sub-oceanic, humid and rainy climate. Its location receives about $875 \mathrm{~mm} / \mathrm{y}$ rainfall distributed consistently all over the year. The rainfall occurs mostly in the form of showers or drizzle. Influenced by the Atlantic Ocean climate, the winter is cold but 
not freezing, while summer is mild. In winter, the average temperature scores around $2 \mathrm{oC}$, while in summer months (July and August) its average score is $17.5 \mathrm{oC}$.

- Challenges for 'Building Skin' Diffusing the direct solar radiation to permit just needed amount of lighting to get into the building is the main challenge for this building skin. However, manipulating sun shading system configurations to avoid their negative impacts on users' visual perception and preventing the building skin out of the rainfall added to this challenge (figure 13).

- Nature-based inspiration The design of the building's shading system is inspired by Birds' feathers. They operate on two different scales to waterproofing bird's skin. On a micro scale, they have minute shafts and barbs with hooks that work at infinitesimal level to close pores and tightly waterproofing the bird. On a macro scale, the feathers are crosshatching in an interlocking pattern to close all the stomas of bird's skin.

- Adaptation Behavior The shading system is developed based on the inspiration of bird's feather performance techniques (figure 14). It consists of about 400.000 stainless steel feathers pivoted to a movable stalks automatically controlled. These 3.150 motorized stalks are following the position of the sun based on signals obtained directly from a weather station mounted on the building's roof. They are designed to have the flexibility of being closed to create a solid enclosure, or open to allow maximum solar exposure. In addition, the variety of metal feathers' shapes -as trapezoid, triangle or rectangle- affects positively the quality of internally reflected and defused sunlight. Their artistic interpretation to the building configurations helps to overcome the negative optical impacts of the sun shading system.
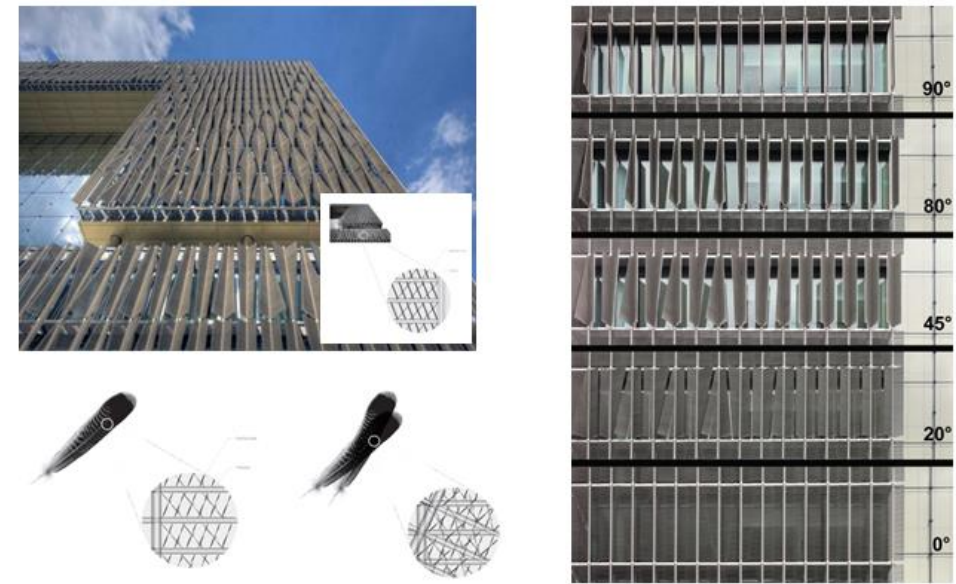

Fig. 14. Biomimicry design based birds' feathers inspiration for the ThyssenKrupp Quarter Essen Q1 building in Essen, Germany. Source [38]

\section{Introducing biomimicry design to new urban developments in Egypt}

Biomimicry has been deeply rooted in Egyptian culture. The remains of the Old civilization show the synchronization between natural phenomena rhythms and different daily and seasonally life aspects of Old Egyptians. The impacts of these strapping linkages are reflected to architectural domain. One example is column capitals as they were mainly following forms of plants (figure 15). They were shaped after lotus (used in the capitals of Luxor temple), papyrus (used in the capitals of Philae temple), and the palm (used in the capitals of Edfu temple) [39]. However these symbolic connections continued to cover many architectural expressions in modern Egypt. The abstraction of 'Lotus' plant was used in many architectural 
Marwa N. Charkas, Towards environmentally responsive architecture: A framework for ..........

icons: Cairo Tower, and the gate of Cairo International fair for example [40]. It is used as a symbol of Old Egyptian cultural sustainability influenced by political aims rather than any environmental considerations. This is clear in Cairo Tower designed by the Egyptian Architect Naoum Shebib and finished in 1961[41]. The tower is a free-standing structure, located at Gezira Island in the middle of the River Nile. Its core structure is covered by a charismatic lattice inspired by the lotus plant. However, the role of this mimic skin doesn't go beyond its political/symbolic role to reflect any biological interactive functions.
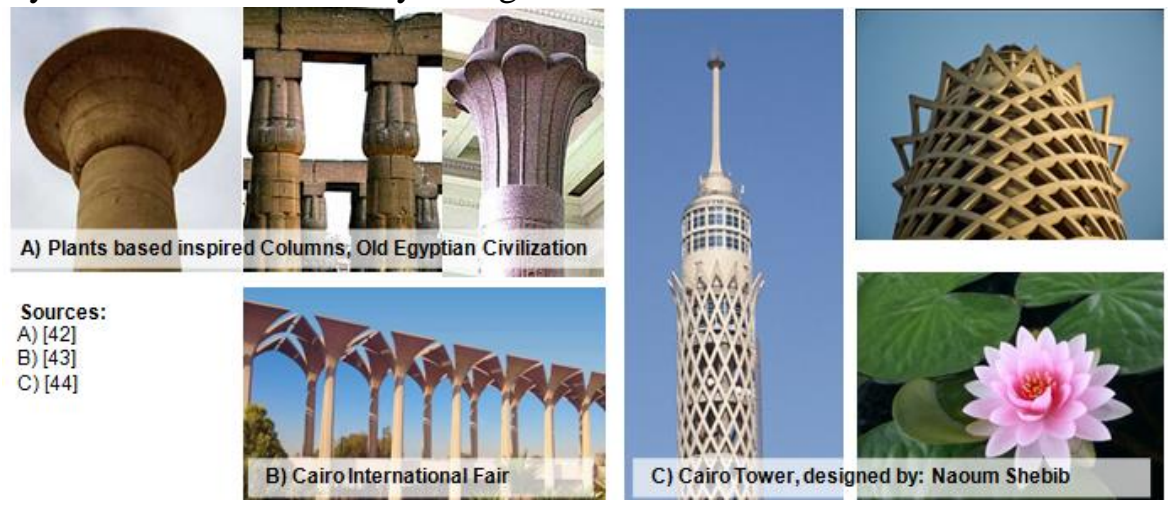

Fig. 15. Examples of Egyptian early biomimicry design

Recently, a new development in Heliopolis district in Cairo -the Gate- comes to introduce the biomimicry approach to new urban development in Egypt as shown in (figure 16). The project is designed by the Belgian architect; Vincent Callebaut covers about $450,000 \mathrm{~m} 2$. It is planned to enclose number of mixed use activates (apartments, retail, and offices) [45]. However, the design reflects Callebaut vision and approach towards challenges facing cities in the first century of the third millennia. He presented his vision in a presentation entitled "diving in architecture Biomimetic... Vincent Cal baut's vision". This vision is based on introducing ecological features within a wider biomimic understanding. He describes the buildings of tomorrow as ones that are Biomimetic and plus-energy buildings that produce their own power [46]. Being consistent with the architect's design approach, the Gate is relying on featured ecological design elements: solar roof, green terraces, sky villas, and a vertical system of gardens and solar heating tubes. Regarding the performed studies, the project is planned to obtain LEED Gold Plus when it is finished [47].

The main feature of the biomimic design in this project is the giant pores shaped as the roof surface curves down. These nine "Mega Trees" as named by Vincent Callebaut [45] work in a similar way to the plants stomata. They are inspired by the exchange process that occurs through plants stomata to allow movement of gases in and out of the intercellular spaces [5]. They have cylindrical steel wired walls covered in plants that help providing natural ventilation and absorb carbon dioxide. In addition, the design develops a computer based articulated mesh surface unfold over all building envelop. This skin will works as to set up the photovoltaic cells, the thermal tubes, and the vertical living walls [48].

Actually the role the project plays by introducing these new ecologically responsive features based on a biomimic approach is leading in this domain. In addition to the direct environmental benefits (is estimated by 50\% energy saving, decrease its carbon footprint, and recycling its gray water), it would be a prototype for a further work in this domain [48]. 

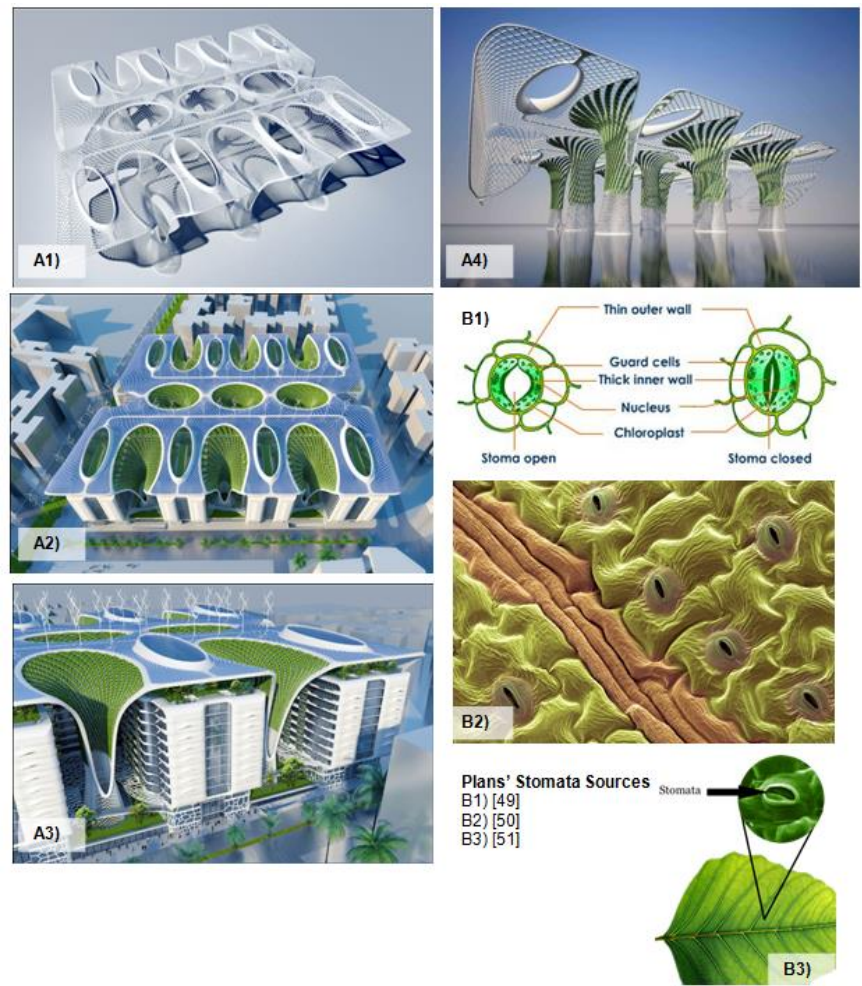

Fig. 16. Biomimicry design based plants' stomata inspiration for the the Gate, Heliopolis, Cairo Egypt. Designed by: Vincent Callebaut. Source: [46]

\section{Conclusion}

Biomimicry based design is a multidisciplinary revolutionary trend in architecture. It has shifted a building conception to be alive interactive being which come to open a new venue for architects' innovation and creativity. This paper develops a frame work for biomimicry based responsive architecture. It presents a comprehensive vision to correlate all of the design problem statement, building's skin challenges, biological based inspiration, technical execution, and finally evolution rhythms of all of these processes. While the framework presents an overview to building's skin biomimicry design configurations, the detailed geographical information is the key to a successful interactive and responsible building's skin design. It keeps the architect informed about the challenges that are facing building skin to mediate the external environmental conditions. Meanwhile, the nature based inspiration sources are unlimited; a collaborative interdisciplinary team is required to come with a proper application of these stimulating features into architectural domain. That's way a large number of interrelated research and experimental areas are developing in this domain. This includes, biological modeling, digital fabrication, electromechanical kinetic studies, and advanced materials investigations.

The examples presented in this paper highlight the inevitable parallel cooperation between architectural and technical / technological domains to come with successful interactive buildings' skin. Architecture ambitions are usually faced with the technical operative limitations that lead to poor building performance especially on long time span. An equal footing development in technical-related domains is the guarantee to have an operative biomimic design. It also shows that, for the same natural based inspiration, 
Marwa N. Charkas, Towards environmentally responsive architecture: A framework for ..........

unlimited architectural expressions could be reached. Architect's creativity is still the corner stone in producing innovative and creative architecture. His perception of updating and informative feedback could reach new visions based on new available technologies. However, understanding the evolution typology of ecological species overtime is the guarantee for a successful nature based inspirations reflected to architectural domain.

Regarding Egypt, it has always been a strong relationship between man and nature. A complete synchronization between daily / seasonally life rhythms and environmental cyclic patterns is rooted in the Egyptian subconscious. However the old architectural expressions in biomimic domain didn't express the dynamic typology of natural processes as they didn't surpass symbolism. Nowadays 'The Gate' a new urban development project located in Heliopolis, Cairo introduces a hopeful start to a real biomimic based building's skin design in Egypt.

\section{REFERENCES}

[1] Fecheyr-Lippens, D., Bhiwapurkar, P. 2017 Applying biomimicry to design building envelopes that lower energy consumption in a hot-humid climate. Architectural Science Review, 1(11), 360[

[2] Webb, M., Aye, L., Green, R. (2015) TRNSYS simulation and thermal performance of biomimetic façade designs in R.H. Crawford and A. Stephan (eds.), Living and Learning: Research for a Better Built Environment: 49th International Conference of the Architectural Science Association 2015, pp.434-443. (C2015, The Architectural Science Association and The University of Melbourne.

[3] VDI 6220 (2011) Bionik: Konzeption und Strategie-Abgrenzung zwischen bionischen und konventionellen Verfahren/Produkten; Biomimetics: Conception and Strategy-Differences Between Biomimetics and Conventional Methods/Products VDI 6220 (Berlin: Beuth). http://m.vdi.eu/uploads/tx_vdirili/pdf/1751320.pdf

[4] Speck, O., Speck D., Horn, R., Gantner, J., sedlbauer, K., (2017). Biomimetic bio-inspired biomorph sustainable? An attempt to classify and clarify biology-derived technical developments. Bioinspir. Biomim. 12011004

[5] López, M., Rubio, R., Martín, S., Ben Croxford, B., and Jackson, R. (2015a). "Active materials for adaptive architectural envelopes based on plant adaptation principles" Journal of Facade Design and Engineering Vol. (3) 27-38

[6] López, M., Rubio, R., Martín, S., Ben Croxford, B., and Jackson, R. (2015b). “Adaptive architectural envelopes for temperature, humidity, carbon dioxide and light control" in 10th Conference on Advanced Building Skins 3-4 November 2015, Bern, Switzerland

[7] Badarnah, L. (2017). Form Follows Environment: Biomimetic Approaches to Building Envelope Design for Environmental Adaptation. Buildings 2017, 7, 40

[8] Badarnah, L. (2012) Form Follows Environment: Biomimetic Approaches to Building Envelope Design for Environmental Adaptation. Buildings 2017, 7, 40

[9] Rossin, K. (2010) Biomimicry: nature's design process versus the designer's process. Design and Nature, WIT Transactions on Ecology and the Environment, Vol 138,Pp 559-570

[10] Hastrich, C. (2006) The Biomimicry Spiral, in Biomimicry Newsletter, The Biomimicry Guild, $\quad$ Vol. $\quad 4.1$ http://biomimicry.typepad.com. newsletter/files/biomimicry_newsletter_v4.pdf

[11] Biomimicry Institute, (2010). Biomimicry: A Tool for Innovation, 2007-2010. http://www.biomimicryinstitute.org/about-us/biomimicry-a-tool-forinnovation. html

[12] Ferguson, A. Siddiqi, K. Lewis, and O. De Weck, (2007). "Flexible and reconfigurable systems: Nomenclature and review," in Proceedigs of ASME 2007 - International Design Engineering Technical Conferences \& Computers and Information in Engineering Conference.

[13] Loonen, R., Trcka, M., Costola, D., Hensen, J. (2013) Climate adaptive building shells: Stateof-the-art and future challenges. Renewable and Sustainable Energy Reviews 25:483-493 
[14] Hofman M. and Dujardin, B., (2008) "European Patent EP1644591: Balcony that can be folded,".

[15] Silver M. and De Weck, O. (2007) "Time-Expanded Decision Networks : A Framework for Designing Evolvable Complex Systems," Systems Engineering, vol. 10, no. 2, pp. 167-186, 2007.

[16] Fawcett, W., Hughes, M., Krieg, H., Albrecht, S., and Vennström, A. (2012). "Flexible strategies for long-term sustainability under uncertainty," Building Research \& Information, vol. 40, no. 5, pp. 545-557, 2012.

[17] Modin, H. (2014) Adaptive building envelopes. Master's Thesis. Department of Civil and Environmental Engineering. Chalmers University of Technology. Sweeden

[18] Sharaidin, K. (2014). Kinetic Facades: Towards design for Environmental Performance. PhD. Thesis. Spatial Information Architecture Laboratory (SIAL) School of Architecture and Design RMIT University

[19] Coelho, M., Pattie Maes, P. (2009) Shutters: A Permeable Surface for Environmental Control and Communication. MIT media Lab.

[20] Mazzoleni, I. (2017). Architecture Follows Nature-Biomimetic Principles for Innovative Design. CRC Press.

[21] Massey, J. (2006). Buckminster Fuller's cybernetic pastoral: the United States Pavilion at Expo 67. The Journal of Architecture, 11(4), 463-483.

[22] Al-Kodmany K. (2018) The Sustainability of Tall Building Developments: A Conceptual Framework. Buildings 2018, 8(1), 7

[23] CTBUH (2018) The Skyscraper Center, The Global tall Building Database of the CTBUH, Al Bahar Towers http://www.skyscrapercenter.com/abu-dhabi/al-bahar-tower-1/9129/

[24] Gbollag, (2013) Biology - Bird Feather Waterproofing Methodologies - Architectural Skins https://nocloudinthesky.wordpress.com/2013/02/13/biology-bird-feather-waterproofingmethodologies-architectural-skins/

[25] Özsavaş, A ., \& A lothman, H . ( 2018). Fashion Inspired b y Architecture: The Interrelationship between Mashrabiya and Fashion World. Journal of History Culture and Art Research, 7(2), 328-351. doi:http://dx.doi.org/10.7596/taksad.v7i2.1480

[26] archeyesmagazine.tumblr.com/post/142513419807/archeyes-the-montreal-biosphere-is-a-museum-in

[27] https://www.imarabe.org/en/architecture

[28] http://www.jeannouvel.com/en/projects/doha-9-high-rise-office-tower/

[29] www.archdaily.com/270592/al-bahar-towers-responsive-facade-aedas

[30] Zvironaite, K., Knol, A. Kneepkens, S. (2014) Kinetica: A playful way through the world of moving facades. ar0531 Innovation and Sustainability., Faculty of Architecture and The Built Environment. On line http://resolver.tudelft.nl/uuid:cabfd871-7ea9-465a-9f78-2a24fdcb9430

[31] Markopoulou, A. (2013). In[form]ations: Digital Matter on Buildings and Cities. in "Advancements in Adaptive Architecture" Manuel Kretzer, Ludger Hovestadt (Eds.) 'Alive, New Design Frontiers', Espace Fondation EDF, Paris, April-September 2013.Pp43-48

[32] Leung C., and Gage, S. (2008) "Dynamic building envelopes," Middle East Art Design and Architecture Magazine, vol. 3, no. 3, pp. 76-80, 2008.

[33] Spanaki, A., Tsoutsos, T., and Kolokotsa, D. (2011) "On the selection and design of the proper roof pond variant for passive cooling purposes," Renewable and Sustainable Energy Reviews, vol. 15, no. 8, pp. 3523-3533, Oct. 2011.

[34] Pan C., and Jeng, T. (2012) "Cellular Robotic Architecture," International Journal of Architectural Computing, vol. 10, no. 3, pp. 319-340, Sept. 2012.

[35] https://newatlas.com/qatars-giant-cactus-biomimicry/10993/)

[36] Meinhold, B. (2018) Inhabitant: Qatar Sprouts a Towering Cactus Skyscraper. In https://inhabitat.com/qatar-cactus-office-building/

[37] Anous,I. (2015). Biomimicry: Innovative Approach in Interior Design for Increased Sustainability. American International Journal of Research in Formal, Applied \& Natural Sciences, 10(1), March-May 2015, pp. 18-27

[38] http://facadesconfidential.blogspot.com/2010/12/thyssenkrupp-quarter-facades-giants.html

[39] Fletcher, B. (1950). A History of Architecture on the Comparative Method. New York, 
Marwa N. Charkas, Towards environmentally responsive architecture: A framework for

[40] Alizak, (2011). Cairo Architecture. https://blog.qualitybath.com/design-inspiration/cairo-architecture/

[41] Macdonald, J. (2018). Cairo Tower, Egypt: The Complete Guide. https://www.tripsavvy.com/cairo-tower-the-complete-guide-4165994

[42] http://www.touregypt.net/featurestories/columns.htm

[43] http://uacciap.org/pm-opens-cairo-international-fair/

[44] http://www.picsnaper.com/p/Cairo-Tower-Image

[45] https://www.businessinsider.com/green-apartment-complex-the-gate-vincent-callebautarchitectures-plans-2017-11/\#the-gate-a-48-million-square-foot-complex-is-being-built-incairos-heliopolis-district-1

[46] http://vincent.callebaut.org/)

[47] Quddus, S. (2014) Vincent Callebaut Designs Sustainable Mixed-Use Complex for Cairo. https://www.archdaily.com/565550/vincent-callebaut-designs-sustainable-mixed-use-complexfor-cairo?ad_medium=widget\&ad_name=more-from-office-article-show

[48] Shahin, H. (2017). The Gate Heliopolis | Vincent Callebaut Architectures. https://www.arch2o.com/gate-heliopolis-vincent-callebaut-architectures/

[49] https://www.tutorvista.com/content/biology/biology-iv/plant-water-relations/stomatalmechanism.php

[50] https://plantstomata.wordpress.com/2017/11/10/stomata-function/

[51] https://www.quora.com/What-are-stomata-1 


\section{نحو عمارة أكثراستجابة للمؤثرات البيئية إطار عمل لتصميم غلاف للمباني محاك للطبيعة}

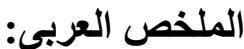

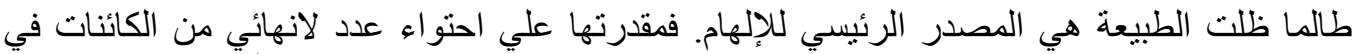

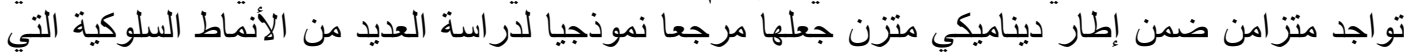

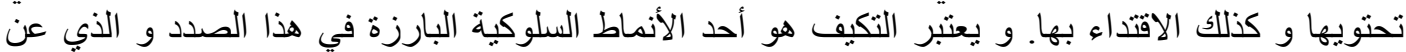

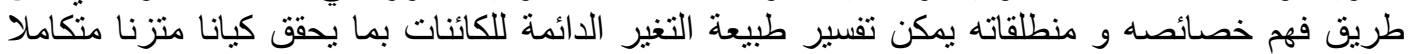

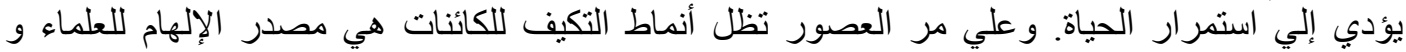

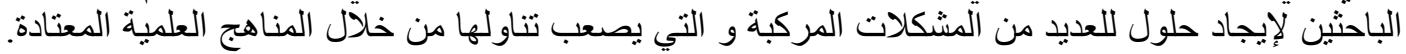
وواحدة من هذه المشكلات الملحة هي مشكلة الحفاظ علي الطاقة بصفة عامة و في مجال المباني بصفة

يقوم هذا البحث بدر اسة الإمكانات التي يتيحها مبدأ محاكاة الطبيعة و الذي يعرف علي الذبان أنه الابتكار المبني

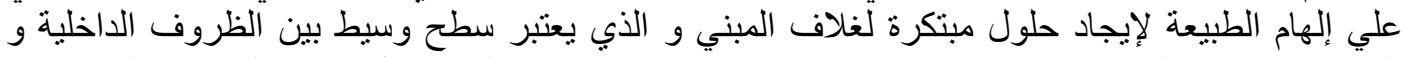

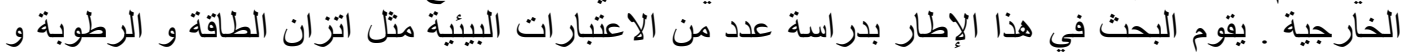

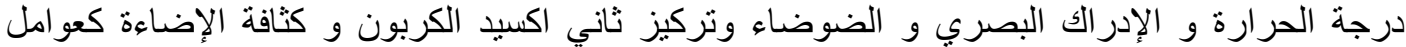

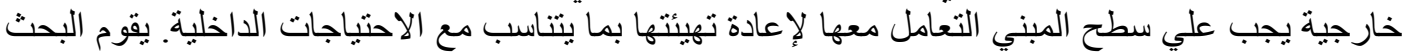
بطرح إطار منكامل لعملية تصميم الغلاف الخارجي للمبني باسلوب محاك للطبيعة مبني علي در اسات مفصلة

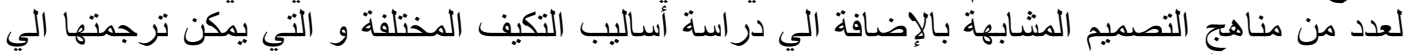

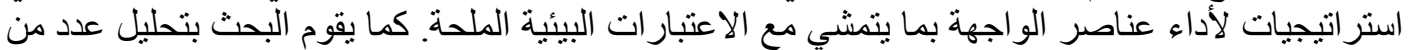

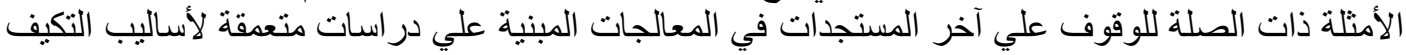

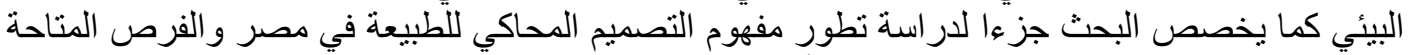

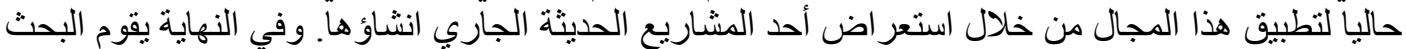

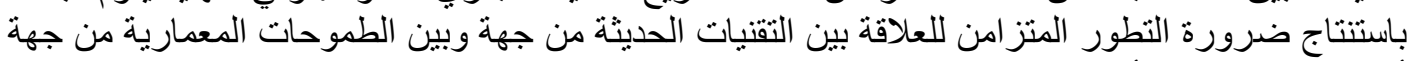

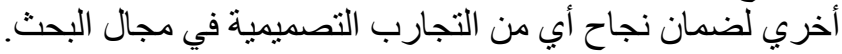

